\title{
Transgenic Quality Characteristics and Economic Analysis of Food
}

\author{
HAN Jing ${ }^{1,}$, WANG Hui ${ }^{2}$ \\ ${ }^{1}$ College of Economics and Management, China Agricultural University, Beijing 100083, China \\ ${ }^{2}$ Information Department, Beijing City University, Beijing 100083, China \\ ahanjing@126.com
}

Keywords: Genetically modified; Food quality; Information asymmetry; Consumer preferences

\begin{abstract}
With the development of transgenic technology, transgenic food is more and more common, which has attracted a great deal of controversy. This article expounded the quality of the food transgenic characteristics of meanings from the product analysis, and analyzed the quality of genetically modified food with the help of the existing economic theory. Genetically modified characteristics of food contain two levels. One type is genetically modified ingredients, influence of genetically modified ingredients for food use value, the society and environment. The other type is the presence of genetically modified ingredients in food, and levels of genetically modified ingredients. In the study of economics, the genetically modified features of food has important meaning, which was showed by the food genetically modified distribution and inspection of quality information, as well as the consumers' preference difference, cognitive and stability.
\end{abstract}

\section{Features of food}

Food features literally refers to the properties and characteristics of food, which is the performance in the raw material, appearance, processing and cooking. From the point of performance, features are the biological, physical and chemical indicators or parameters of the product. For food production, transgenic technology is a kind of new breeding techniques; it realized the biological properties of genetic modification without the traditional sexual breeding process through genetic recombination. Transgenic breeding process mainly includes three stages, the first is genetic screening and artificial separation of genes, and then build the genetic transformation of the carrier, the final is to import the purpose genes. Gm varieties obtained by transgenic technology enter into agricultural production, and was seen as raw materials for the food or for food processing. Because of orientation and accuracy of the transgenic technology, it has great potential in food production. At present, genetically modified (GM Traits) has been in commercial production is mainly herbicide resistance and resistance to pesticides. From existing types of food, genetically modified foods are generally has a corresponding traditional food, which are almost identical on existing food features, the most important difference is in genetically modified ingredients. That is to say, with the emergence of transgenic technology and transgenic food, genetically modified (gm) features have become food intrinsic features.

\section{Quality of food}

Quality is an important concept in economics and management. At present, the concept of product quality put forward by the international standard organization is mostly used, by which quality is the meeting degree of a set of inherent characteristics meet the express, implied or must-fulfill requirements (ISO9000:2000). According to above definition, food quality refers to a set of inherent characteristics that meet the social public and consumers express, implied or usually must fulfill the requirements of the degree. From the concept, the key point lies in the "quality characteristics" and "meet requirement". Quality feature pay attention to product quality use value, meeting the demand on the evaluation of consumers. Generally speaking, the food quality is mainly the use of the food itself value and character. Among them, food characteristic comply with the policy, laws and regulations, and customer safety and experience to eat have a significant impact on 
quality characteristics. [1]Evaluation of food quality depends on personal preferences and levels of knowledge. Food scientists emphasize the measure of food quality, consumer marketers emphasizes food quality self feelings.

Genetically modified characteristics of food are important quality characteristics of food. From the point of product properties, transgenic technology is an important technology; food production is an important intrinsic characteristic of food, which is a potential index of food quality. From the point of consumer evaluation, gm features has a close relationship between consumer needs and expectations. Along with the proliferation of genetically modified food in people's daily lives, genetically modified (gm) has received widespread attention, which has formed two kinds of different points of view. Transgenic technology supporters say that transgenic technology can not only improve crop yield, reduce the production cost and improve the quality of the product, but also indirectly reduce pesticide chemical products such as damage to the environment. Supporters of gm food insist genetically modified foods are an important means to solve the world food crisis. Opponents of genetically modified (gm) technology talk from the perspective of ecological risk, environmental pollution, and ethical criticism. [2]Opponents of genetically modified (gm) food suspected the credibility of the scientific evidence, concerns about the potential risk of genetically modified food may be unknown, and the cumulative effect of long-term consumption of genetically modified food on human body. In this debate, consumer evaluation of genetically modified (gm) food and non-gm food is often different, and different consumers have different evaluation on genetically modified food. Therefore, from the understanding of the food quality, food transgenic characteristics are important quality characteristics of food.

\section{Quality composition of food transgenic characteristics}

Food transgenic characteristics, namely the characteristics of the food of genetically modified (gm), are intrinsic characteristics associated with the genetically modified ingredients of food. From analysis, genetically modified features not only reflect the technical features of the food, it is also a special inner quality characteristic of food. [3]Starting from the concept of quality, the quality of genetically modified characteristics of meaning is a genetically modified (gm) features meet express, implied or usually must fulfill the requirements and expectations. Quality of genetically modified food includes not only the presence of genetically modified ingredients in food, it also include the type of genetically modified ingredients, content of genetically modified ingredients in food, use value and the influence of social, environmental, etc from genetically modified ingredients.

From the point of food quality constitute, the understanding of the food quality is different with different elements. Transgenic characteristics is an important feature of food, this article use the following formula to show food quality:

$$
Q(q)=f\left(q_{g}, q_{1}, q_{2}, q_{3}, q_{4}\right)
$$

In the type, $q_{g}, q_{1}, q_{2}, q_{3}, q_{4}$ respectively mean genetically-modified properties, basic characteristics, nutrition characteristics, functional characteristics, and other physical and chemical characteristics. $q_{g}, q_{1}, q_{2}, q_{3}, q_{4}$ is a system with comprehensive index system. Take genetically-modified attributes as an example, it can be represented as:

$$
q_{g}=f_{g}\left(q_{g_{0}}, q_{g_{1}}, q_{g_{2}}, q_{g_{3}}\right)
$$

$q_{g_{0}}, q_{g_{1}}, q_{g_{2}}, q_{g_{3}}$ are genetically modified input characteristics, nutritional improvement, functional improvement, and other improvements. For the first generation of genetically modified food, genetically modified feature gave priority to agronomy interests, having less effect on the consumers, at the time $q_{g}=q_{g_{0}}$.

Food quality includes quality and quantity, the contribution rate of some characteristics of the product quality and quantity is large, while some features of small contribution. From the point of view of the contribution of food quality, the relationship between and exegetical modification attributes food quality can be written as: 


$$
P(q)=\sum_{i=1}^{n} \gamma_{i} P\left(q_{i}\right)+\gamma_{g} P\left(q_{g}\right)
$$

From above formula, we can also calculate the genetically modified ingredients on the quality of the food contribution rate:

$$
\% P_{g}=\gamma_{g} P\left(q_{g}\right) /\left[\sum_{i=1}^{n} \gamma_{i} P\left(q_{i}\right)+\gamma_{g} P\left(q_{g}\right)\right]
$$

\section{Economic meaning}

The analysis of the products is the foundation of economic research. With the change of the product features, the relationship between the producers and traders will follow the corresponding change. Transgenic characteristics are the special inherent quality characteristics of food, which has two aspects of the important significance in the study of economics, quality information of food asymmetry and consumer preferences.

\section{Transgenic quality information of food is asymmetry}

Information asymmetry is an important part of the study of economics to show the information structure problem in incomplete information market. Asymmetry is a common phenomenon in the economic life of information. [4]The quality of the food market information being asymmetry refers to that in the food trade activities, the choice of the information is not complete, and one part has better control of the information.

\section{1) The quality information distribution and transgenic characteristics of food}

According to the distribution of the quality information between producer and consumer products, Nelson (1970), Darby and Kami (1970) divide products into the search quality, experience, quality and trust. For search product, we can determine the quality of the consumers before buying. Experience goods consumers observe or perception in the consumption. Trust products' quality cannot be judged even after consumption. Food is with multi-dimensional quality characteristics, and these qualities often have different characteristics of information. For genetically modified quality features, consumers cannot judge the existence of the genetically modified ingredients and content whether prior to or after the consumption. Because of the characteristics of information, the genetically modified ingredients are the trust characteristics of food. [5]

\section{2) The quality information inspection and transgenic characteristics of food}

In addition to the distribution of quality information, the product quality can also be divided from two dimensions of observable and verifiable division according to the features of information inspection (Hou Shouli, 2005). Observed quality is based on consumers eventually capture information, which consumer can judge through his own experience in consumption. Testable quality of the feature is based on the quality of professional judgment, which is the quality level can be described or quantitative, and can be verified properly for special institutions. For genetically modified food features, it is difficult for consumer to judge, even if some foods contain genetically modified ingredients, consumers are not professional enough for judgment and detection. Through specialized inspection agency inspection, under the certain error range can determine whether to contain genetically modified ingredients in food and the type and content of genetically modified ingredients. But, for whether the transgenic technology is used, it is a genetically modified process characteristics, even if genetically modified food raw materials is used in the process of production, the final product may have genetically modified ingredients residual or genetically modified ingredients are not sufficient to support the inspection results. [6] Therefore, from the point of the test characteristics of information, the final product is difficult to observe whether there is a genetically modified ingredients but usually easy to inspection.

In examine dimensions, transgenic characteristics differences show the different costs. Examination is relatively easy for some food genetically modified ingredients with low testing cost while for some genetically modified food ingredient detection is relatively difficult, the testing cost is higher. The volume of the testing cost reflects the characteristics of the testing technology and also reflects the characteristics of the gm and level of genetically modified ingredients. For whether 
the material contain genetically modified ingredients is used in production process, except for the final test in the food, we also need to increase supervision and inspection in the intermediate links.

\section{Consumer preferences of food transgenic characteristics}

According to the theory of the consumer, the consumer purchase decision making is limited by a budget constraint and depends on the preferences of the consumer. [7]Consumer preferences are degree of be fondness of consumers on goods or commodities combination, which is consumers' subjective order. In economics theory, preference relations is taken as the most primitive, the most basic features, which is a personal characteristic, quality, culture, risk consciousness of restrictions, such as reflect individual needs, interests and hobbies.

\section{1) The differences in preferences}

Consumers have different preferences or attitude in the genetically modified properties, namely $P\left(q_{i}\right)$ in formula in 2-3 quality evaluation varied due to the different consumers. This may be especially significant difference, some consumers agree to genetically modified features, $P\left(q_{i}\right)$ is positive, some consumers have refused to genetically modified features, $P\left(q_{i}\right)$ negative.

\section{2) The cognition and stability of preference}

Transgenic technology originated in laboratory studies, consumers' knowledge and understanding ability is limited. Moreover, genetically modified food features are new features, contact and understand is different from consumer to consumer. Therefore, consumers' food transgenic attribute preference is different on the cognitive and the stability of the preferences.

According to consumer's perception of preferences and stability, consumers of genetically modified preferences can be divided into four categories, as shown in figure 1 .

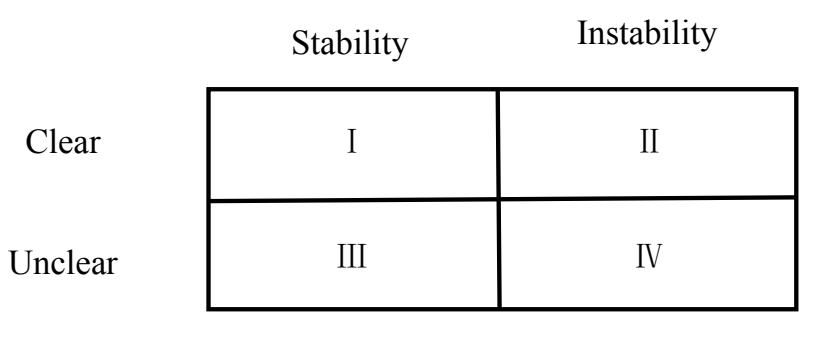

Figure 1 GM preferences of consumers

\section{Summary}

As an important material form to sustain human life, food is one of the important results of agricultural and industrial production and transaction object. Different from industrial product design and manufacturing, food ingredients and characteristics are the core of the food quality research. Before the appearance of transgenic food, the quality of agricultural products is especially relatively stable, mainly involves two major topics in nutrition and safety. Genetically modified organisms are the important raw material for food production, and its genetic material is changed by transgenic technology. From the perspective of the composition analysis of food, food obtained from genetically modified organisms has certain genetically modified ingredients.

\section{References}

[1] Devos Y, Maeseele P, Reheul D, et all. Ethics in the societal debate on genetically modified organismsL a (re)quest for sense and sensility[J]. Journal of Agricultural and Environmental Ethics, 2008, 21: 29-61.

[2] Labrecque J, Charlebois S, Spiers E. Can genetically modified foods be considered as a dominant design. An actor-network theory investigation of gene technology in agribusiness [J]. British Food Journal, 2007, 109(1): 81-98. 
[3] Wohlers A E. Regulating Genetically Modified Food [J]. Politics and the Life Sciences, 2010, 29(2): 17-39.

[4] Deng Jiaqiong, Agricultural biotechnology process view and realization ways of agricultural leading enterprises in China [J], economic issues to explore, 2011 (12) : 81-86.

[5] Wang Xiuqing, Sun Yunfeng. Quality of the food market in our country signal problems [J]. China's rural economy, 2002 (5): 27-32.

[6] Hou Shouli. The label of the regulation of genetically modified food problem research [D]. Shanghai: Shanghai Jiaotong university, 2005. 